\title{
Assessing hygiene indicators in two dairies in Algeria in producing pasteurized milk
}

\author{
Regguem Souad (D), Hamdi Taha Mossadak (D) and Bouayad Leila (i) \\ Laboratory of Food Hygiene and Quality Insurance System (HASAQ), Higher National Veterinary School, Rue Issad Abbes, \\ Oued Smar, Algiers 16000, Algeria. \\ Corresponding author: Regguem Souad, e-mail: regguems@live.fr \\ Co-authors: HTM: moussahamdi@hotmail.com, BL: leilabouayad@hotmail.com \\ Received: 09-04-2021, Accepted: 28-07-2021, Published online: 04-09-2021
}

doi: www.doi.org/10.14202/vetworld.2021.2317-2324 How to cite this article: Souad R, Mossadak HT, Leila B (2021) Assessing hygiene indicators in two dairies in Algeria in producing pasteurized milk, Veterinary World, 14(9): 2317-2324.

\begin{abstract}
Background and Aim: There is a worldwide controversy about the choice of microbial flora for use as process hygiene indicators. This study aimed to evaluate the pertinence of using either coliforms or Enterobacteriaceae (EB) as process hygiene indicators in the pasteurized milk production line. Two flora families and total flora were used as bacterial indicators in some stages of pasteurized milk production line to identify the origin of post-pasteurization contamination and compare the results obtained for each flora. In addition, the bacteriological profile of isolated coliforms and EB was developed.
\end{abstract}

Materials and Methods: One thousand and two hundred samples of pasteurized cow milk and surfaces (pipes and tank) at various processing stages were taken from two dairies in the northern region of Algeria. The total microbial flora (TF), total coliforms (TC), thermotolerant coliforms, and EB were enumerated, following the recommendations of ISO 4833:2006, ISO 4832:2006, and ISO 21528-2:2017 methods, respectively. The bacteriological profile was determined using the API $20 \mathrm{E}$ and $10 \mathrm{~S}$ tests (bioMérieux, France). Furthermore, the cleaning efficiency and disinfection protocol of surfaces were evaluated using contact agar slides 1 (Liofilchem ${ }^{\mathrm{TM}}$, Italy).

Results: Enumeration of the different indicators shows that the highest contamination rate is recorded by the total flora in the two units, 3.28 and $3.78 \log \mathrm{CFU} / \mathrm{mL}$, respectively. $\mathrm{EB}(-0.60 \log \mathrm{CFU} / \mathrm{mL})$ at post-pasteurization stage in Unit 1 and coliforms $(0.44 \log \mathrm{CFU} / \mathrm{mL})$ at the pasteurized packaged milk stage in Unit 2 are the least significant germ families. The lowest compliance rates of bacterial contamination were reported for total flora $(82-85 \%)$ at the three sampled sites in Unit 2. In comparison, the highest was reported in Unit $1(99.8 \%)$ and $2(98 \%)$ by the EB indicator. Assessing the surface cleaning and disinfection protocol compliance shows that the tank records the highest non-compliance rates for EB and TF $(4 \%$ and $3 \%)$ in Unit 2. EB are represented in both units by various species. Acinetobacter baumannii in Unit 1 and Enterobacter cloacae in Unit 2 are the common species of the three indicator families. Acinetobacter and Enterobacter in Unit 1, Escherichia, Citrobacter, Enterobacter, Klebsiella, and Hafnia in Unit 2 are the most time persistent bacterial genera along the production line. Stenotrophomonas, Serratia, Salmonella, Enterobacter, and Escherichia are common genera in both units.

Conclusion: The results obtained show no difference in the use of EB or TC as hygiene indicators. However, if the objective is to identify the species of bacterial populations, using EBs are the most appropriate.

Keywords: coliforms, enterobacteria, indicators, pasteurized milk, process hygiene, total microbial flora.

\section{Introduction}

The dairy industry in developing countries has significant growth potential that is constantly evolving due to the increasing demand for milk and dairy products [1]. Milk provides the human body with all essential amino acids [2]; however, it is unsterile and still contains several microorganisms, which may be pathogenic, causing foodborne illness, nonpathogenic, causing spoilage of the product $[3,4]$. In addition, because of their composition, milk and dairy products are an excellent growth medium for microorganisms $[4,5]$.

Copyright: Souad, et al. Open Access. This article is distributed under the terms of the Creative Commons Attribution 4.0 International License (http://creativecommons.org/licenses/by/4.0/), which permits unrestricted use, distribution, and reproduction in any medium, provided you give appropriate credit to the original author(s) and the source, provide a link to the Creative Commons license, and indicate if changes were made. The Creative Commons Public Domain Dedication waiver (http://creativecommons.org/ publicdomain/zero/1.0/) applies to the data made available in this article, unless otherwise stated.
Milk bacterial contamination causes major economic losses and various hazards for human health. More than $20 \%$ of milk production in developing countries is lost due to early spoilage and losses due to microbial contamination at different stages of the production [5]. Foodborne diseases caused by pathogenic microorganisms are more frequent than those due to harmful chemicals and plants [6]. The application of heat treatment, such as pasteurization, is sufficient to reduce $99.99 \%$ of pathogenic and non-pathogenic microorganisms in raw milk [7]. This treatment eliminates or inactivates all vegetative forms of bacteria, psychrotrophic microorganisms, yeasts and molds, and certain unwanted enzymes while preserving the food value of milk $[4,8]$.

Bacterial contamination of pasteurized milk may have several origins: Manufacturing equipment surfaces, employees' hands, packaging materials, and deficient pasteurization $[9,10]$. The latter would 
allow pathogenic bacteria to survive, leading to production incidents in the post-pasteurization stages (PAST) and subsequently causing health problems for consumers [11,12].

Milk pasteurization has been described as a critical control point (CCP) for implementing food safety management systems [10,11]. Determination and monitoring of CCPs require identifying the origins of the contamination, determination of its persistent nature, and planned corrective actions. Biofilms, the vector of persistent contamination, are bacterial communities that adhere to processing equipment and resist cleaning and disinfection, resulting in continuous contamination of milk and dairy products over time [13]. In addition, the continuous formation of biofilms leads to their resistance to removal, particularly when using cleaning in place systems [14].

An indicator organism is defined as a marker, whose presence reflects, on the one hand, the sanitary status of either a food or an environment, contamination post-application of sanitation treatments, hygienic handling, and storage conditions [14]. However, it can reveal the possible presence of pathogens that are a potential hazard to public health $[14,15]$. To select the most relevant indicator, it is more appropriate to follow the evolution of several of them over a given period to retain only the one that seems the most sensitive to deviations from hygiene practices [15].

In the dairy industry worldwide, the main groups of indicator bacteria used in post-pasteurization contamination (PPC) are coliforms, Enterobacteriaceae (EB), total Gram-negative, Pseudomonas, and Gram-positive spore-forming bacteria [16]. In the US dairy industry, coliforms have been used since 1914 as indicator organisms [17]. They were recommended by the US Public Health Service in the first edition of the Pasteurized Milk Ordinance published in $1924[6,7]$. They continue to be used for this purpose. However, recent studies indicate that only a fraction is of fecal origin, while most would come from the environment [14]. Furthermore, the search for coliforms, which are involved in less than $50 \%$ of PPC of milk, does not detect Pseudomonas and other Gram-negative non-coliform bacteria [17]. This leads to question about the relevance of using coliforms as hygiene indicators for dairy products $[5,14]$. In Europe, another widely used group of indicators is proposed for the dairy industry; it is the EB family and the total Gram-negative bacteria $[13,16]$.

This study aimed to evaluate the pertinence of using either coliforms or EBs as process hygiene indicators in the pasteurized milk production line. Two flora families and total flora were used as bacterial indicators in some stages of pasteurized milk production line to identify the origin of post-pasteurization contamination and compare the results obtained for each flora. In addition, the bacteriological profile of isolated coliforms and EBs was developed. There is no Algerian regulatory framework on the indicator to be used to assess the hygiene of processes. The results of this study should provide scientific support to decide on the appropriate indicator to use.

\section{Materials and Methods}

\section{Ethical approval}

The microorganisms studied during the pasteurized milk production process do not require the use of live animals, so no ethical approval is necessary.

\section{Study period, location, and sample collection}

The study was conducted from October 2017 to January 2020. One thousand and two hundred samples were collected from two dairies in the northern region of Algeria. The first one (Unit 1) belonging to the private sector is located in the Wilaya of Tizi-Ouzou; the second (Unit 2) to the public sector is located in the Wilaya of Boumerdès. Twice a week, samples are collected as follows: For each unit, three stages were chosen to collect samples: Immediately after pasteurization (PAST), from the collection tank (Tank), and finally, the pasteurized packaged milk (PPM). One hundred samples of milk and 100 samples of the surface were collected at each selected stage (the surfaces of the tanks by swabbing and the pipes by rinsing). The samples were immediately transferred to the food microbiology laboratory of the National Veterinary School, where they were analyzed on the same day they were collected. The surface samples were taken according to the ISO 18593/2004 method [18].

\section{Bacteriological analysis of milk}

Samples were analyzed for total microbial flora (TF), total coliforms (TC), thermotolerant coliforms (TTC), and enterobacteria (EB) using the following standard methods: ISO 4833: 2006 [19] on plate count agar (PCA); ISO 4832:2006 [20], which includes coliform counts on violet-red bile lactose agar and ISO 21528-2:2017 [21] on violet-red bile glucose agar (VRBG), respectively. In addition, API 20E and 10S strips (bioMérieux, France) were used for bacteriological profile identification. Compliance rates of bacterial contamination for coliforms, total flora, and enterobacteria were evaluated and interpreted according to the Algerian Interministerial Decrees setting microbiological criteria for food products (N35/1998 and N39/2017) [22,23].

\section{Analysis of surface samples}

Contact agar slides with one face to detect EB (VRBG agar) and total flora counting (PCA agar) were used to evaluate the efficiency of cleaning and disinfection protocol of surfaces in contact with milk. The results of the enumeration are given in $\mathrm{CFU} / \mathrm{cm}^{2}$ of the surface. Compliance is established at $1 \mathrm{CFU} / \mathrm{cm}^{2}$ for enterobacteria and $10 \mathrm{CFU} / \mathrm{cm}^{2}$ for total flora.

\section{Statistical analysis}

Software R v.3.6.3 (https://www.r-project.org/) was used to analyze the data. Chi-square test and descriptive statistics were used to establish the average and the satisfaction rate. In addition, the ANOVA 
and Tukey tests were used to compare the compliance rates of the indicators.

\section{Results}

The overall rate of bacterial contamination of milk

The enumeration of the different indicator flora shows that the highest contamination rate is recorded by the total flora in the two units, 3.28 and $3.78 \mathrm{log}$ $\mathrm{CFU} / \mathrm{mL}$, respectively. The least important germ families are EB $(-0.60 \log \mathrm{CFU} / \mathrm{mL})$ at the PAST stage (after pasteurization) in Unit 1 and coliforms $(0.44$ $\log \mathrm{CFU} / \mathrm{mL}$ ) at the pasteurized packaged milk stage in Unit 2 (Figure-1). In terms of total and TTC, variable values ranging from 1.13 to $1.48 \log \mathrm{CFU} / \mathrm{mL}$ and 0.62 and $1.35 \log \mathrm{CFU} / \mathrm{mL}$ were observed at different sampling sites in Unit 1. However, in Unit 2, tank (2.52 and $2.49 \log \mathrm{CFU} / \mathrm{mL})$ and PPM (0.44 log $\mathrm{CFU} / \mathrm{mL}$ ) showed similar mean contamination values as found at both sites, respectively.

\section{Compliance rate}

The highest compliance rates were obtained at the first sampling site (PAST) $(99.8 \%$ and $98 \%)$ in both units using the EB indicator. Conversely, the lowest rates were recorded in Unit 2 by total flora (between $82 \%$ and $85 \%$ ) in all three sites (Table-1).

\section{Evaluation of the efficiency of the cleaning and dis- infection protocol}

In Unit 1, at the three examined sites, $99 \%$ compliance was observed. While, in Unit 2, 4\% and 3\% of non-compliant samples were reported by EB and TF, respectively, in tank (Table-2).

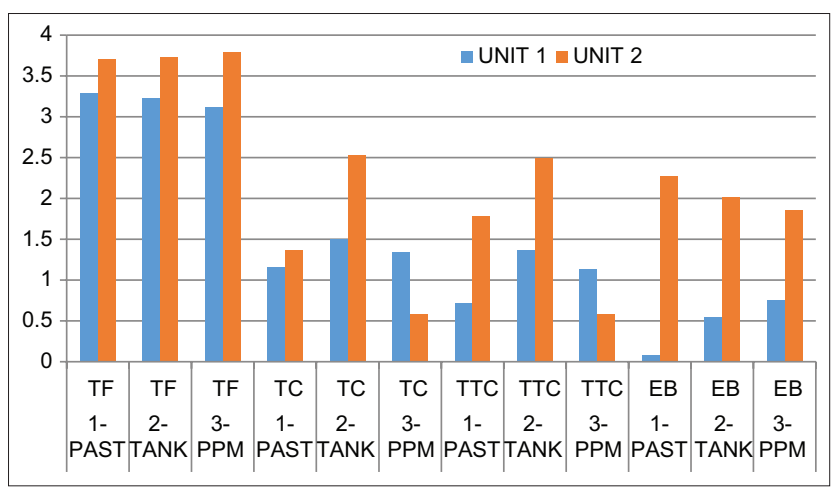

Figure-1: Distribution of the indicators along the production line for both units. Total microbial flora, total coliforms, thermotolerant coliforms, and Enterobacteriaceae.
Evolution of the indicators along the process stages

Three combinations of parameters were considered to assess the evolution of the indicators along the production line. Considering the indicator/line parameters, there was no statistically significant difference between the indicators studied during the three stages of the production process $(p>0.05)$ in the two units (Table-3). However, considering the stage/indicator parameters, the difference between stages was significant for all indicators in Unit $1(\mathrm{p}<0.05)$ compared with Unit 2, which revealed only one difference at the PAST stage at $\mathrm{p}=0.00133$ (Table-4). Finally, a pairwise comparison of the various indicators (indicator/indicator) revealed a significant disparity only when the TF was paired with the other indicators $(p=0.0001)$.

\section{Bacterial diversity of hygiene indicators}

The identification of different species from different isolated indicator families showed that EB were represented by several species (4) in Unit 1: Enterobacter cloacae (Eb cl), Escherichia coli 1 (Ec 1), Salmonella choleraesuis ssp. arizonae, and Stenotrophomonas maltophilia; while TC dominated by Enterobacter aerogenes (Ebae) and Serratia odorifera. The species identified in the TTC family are Ec 1 and Klebsiella oxytoca (Klbox).

Species identification revealed the presence of the non-colif-EB group Acinetobacter. The species with the highest repetition rate is Ec 1 for coliform thermotolerant followed by $\mathrm{Eb} \mathrm{cl}$ for EB (Figure-2). Figure-3 shows that in Unit 2, 13 bacterial species reported are grouped in the EB family, seven coliforms, and six in TTC. Only one species, $\mathrm{Eb} \mathrm{cl}$, is common for all three families (TC, TTC, and EB). However, several species are common in two families: Ec 1, Ebae, Hafnia alvei, and Rahnella aquatilis for thermotolerant and TC; Citrobacter freundii for EB and TC, and Klebsiella pneumoniae for EB and TTC. The highest repetition rate was observed in Ec 1(6) followed by Klbox and $\mathrm{Eb} \mathrm{cl}$ with the same rate (5).

The distribution of the established bacterial genera varieties along the production line (Figure-4) shows that Acinetobacter and Enterobacter are the most persistent genera over time in Unit 1, while Escherichia, Citrobacter, Enterobacter, Klebsiella, and Hafnia are the most persistent along the process in Unit 2 . In both units, we have registered a continuous

Table-1: Compliance rate of bacterial contamination of milk in both units.

\begin{tabular}{|c|c|c|c|c|c|c|c|c|}
\hline \multirow[t]{3}{*}{ Sample stage } & \multicolumn{8}{|c|}{ Compliant samples \% } \\
\hline & \multicolumn{2}{|c|}{ TC $(m=1)$} & \multicolumn{2}{|c|}{ TTC $(m=0)$} & \multicolumn{2}{|c|}{ EB $(m=M=10)$} & \multicolumn{2}{|c|}{$\operatorname{TF}\left(\mathrm{m}=3 \times 10^{4}\right)$} \\
\hline & U1 & U2 & U1 & U2 & U1 & U2 & U1 & $\mathbf{U} 2$ \\
\hline PAST & 98 & 94 & 98 & 96 & 99,8 & 98 & 95 & 85 \\
\hline TANK & 94 & 90 & 95 & 94 & 98.6 & 94,8 & 96 & 84 \\
\hline PPM & 96 & 97 & 97 & 97 & 99.4 & 97.8 & 97 & 82 \\
\hline Mean & 96 & 93.66 & 96.66 & 95.66 & 99.26 & 96.86 & 96 & 83.66 \\
\hline
\end{tabular}

$\mathrm{TF}=$ Total microbial flora, $\mathrm{TC}=$ Total coliforms, TTC=Thermotolerant coliforms, $\mathrm{EB}=$ Enterobacteriaceae, U1=Unit 1, U2=Unit $2 ; \mathrm{m}=$ Value below which the quality of the product is considered satisfactory, $M=$ Value above which the quality of the product is considered unacceptable, PAST=post-pasteurization stages, TANK=tanker milk, PPM=pasteurized packaged milk 
Table-2: Evaluation of the efficiency of the cleaning and disinfection protocol in both units.

\begin{tabular}{lccc}
\hline Sample stage & TF $(\mathbf{C})$ & & EB $(\mathbf{C})$ \\
\cline { 2 - 2 } & $>\mathbf{1 0} \mathbf{~ c f u / \mathbf { c m } ^ { \mathbf { 2 } }}$ & & $\mathbf{> 1} \mathbf{~ c f u} / \mathbf{c m}^{\mathbf{2}}$ \\
\hline PAST (U1) & $99 \%$ & $99 \%$ \\
TANK (U1) & $99 \%$ & $99 \%$ \\
PPM (U1) & $99 \%$ & $99 \%$ \\
PAST (U2) & $99 \%$ & $99 \%$ \\
TANK (U2) & $97 \%$ & $96 \%$ \\
PPM (U2) & $98 \%$ & $96 \%$ \\
\hline
\end{tabular}

$\mathrm{C}=$ Compliant, $\mathrm{TC}=$ Total coliforms, EB=Enterobacteriaceae, $\mathrm{PAST}=$ post-pasteurization stages, $\mathrm{TANK}=$ tanker milk, PPM $=$ pasteurized packaged milk

Table-3: Assessment of the indicator parameter and production line.

\begin{tabular}{|c|c|c|c|c|c|c|c|c|}
\hline Sample stage & $\mathbf{T}$ & C & & TC & E & B & $\mathbf{T}$ & $\mathbf{F}$ \\
\hline $\begin{array}{l}\text { PAST, TANK, } \\
\text { PPM }\end{array}$ & U1 & U2 & U1 & U2 & U1 & U2 & U1 & U2 \\
\hline p-value & 0.39 & 0.51 & 0.5 & 0.56 & 0.5 & 0.4 & 0.07 & 0.32 \\
\hline
\end{tabular}

$\mathrm{p}=$ Measure of the probability. TF=Total microbial flora, $\mathrm{TC}=$ Total coliforms, $\mathrm{TTC}=$ Thermotolerant coliforms, $\mathrm{EB}=$ Enterobacteriaceae, $\mathrm{PAST}=$ post-pasteurization stages, TANK = tanker milk, PPM = pasteurized packaged milk

Table-4: Assessment of the step parameter and indicators.

\begin{tabular}{|c|c|c|c|c|c|c|}
\hline \multirow{2}{*}{$\begin{array}{l}\text { Indicator } \\
\text { TC, TTC, EB, } \\
\text { and TF }\end{array}$} & \multicolumn{2}{|c|}{ PAST } & \multicolumn{2}{|c|}{ TANK } & \multicolumn{2}{|c|}{ PPM } \\
\hline & U1 & U2 & U1 & U2 & U1 & U2 \\
\hline p-value & 0.006 & 0013 & 0.0003 & 0.114 & 0.0054 & 0.70 \\
\hline
\end{tabular}

$\mathrm{TF}=$ Total microbial flora, $\mathrm{TC}=$ Total coliforms, $\mathrm{TTC}=$ Thermotolerant coliforms, EB=Enterobacteriaceae, $\mathrm{PAST}=$ post-pasteurization stages, $\mathrm{TANK}=$ tanker milk, $\mathrm{PPM}=$ pasteurized packaged milk, $\mathrm{PPM}=$ pasteurized packaged milk

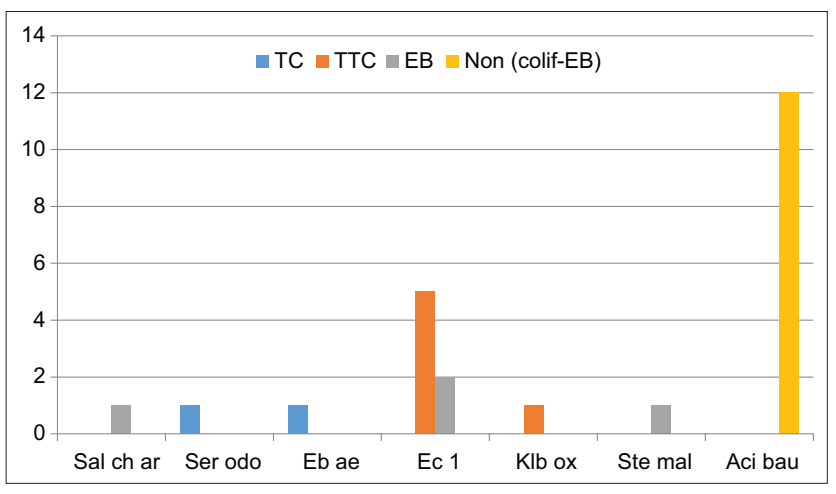

Figure-2: The major bacterial species isolated from the various hygiene indicators in Unit 1. Acinetobacter baumannii=Aci bau, Escherichia coli 1=EC 1, Enterobacter aerogenes $=\mathrm{EB}$ ae, Enterobacter cloacae $=\mathrm{EB} \quad \mathrm{cl}$, Klebsiella oxytoca=KIb ox, Serratia odorifera=Ser odo, Stenotrophomonas maltophilia=Ste mal, Salmonella choleraesuis ssp. arizonae $=\mathrm{Sal}$ ch $\mathrm{ar}$.

presence of the genus Enterobacter throughout the process. Stenotrophomonas, Serratia, Salmonella, Enterobacter, and Escherichia are common genera in both units. In addition, Citrobacter, Hafnia, Rahnella, and Pantoea genera were found in Unit 2 only.

\section{Discussion}

The overall rate of bacterial contamination

The means of contamination of the total flora reported in Units 1 (3.20 log CFU/mL) and 2 (3.74 log $\mathrm{CFU} / \mathrm{mL}$ ) are similar to those recorded in Cameroon (3.79 $\pm 0.62 \log \mathrm{CFU} / \mathrm{mL}$ ) [24] and Egypt (3.17 $\log$ $\mathrm{CFU} / \mathrm{mL}$ ) [25]. Higher contamination levels, such as those recorded in Kenya (6.05 $\log \mathrm{CFU} / \mathrm{mL})$ [26] and in Ethiopia (6.60-7.54 $\log \mathrm{CFU} / \mathrm{mL}$ ) [27], have been seen in other studies. This could be due to air, packaging, drains, and employees' contamination [17]. One study found that hygiene practices are insufficient in the entire milk production system in developing countries [28].

The rate of non-compliant samples shown by the total flora in Unit 1 is $4 \%$, and Unit 2 is $16.33 \%$. (Table-1). In Algeria [29,30], rates recorded in recombined milk vary from $0 \%$ to $2.17 \%$, respectively. Other reports have found non-compliance rates ranging from $21.4 \%$ to $100 \%[2,26,31,32]$.

Increased bacterial contamination of treated milk may also lead to inadequate processing procedures, poorly maintained facilities, and staff not trained in hygienic practices. The microbial quality of pasteurized milk is crucially influenced by a high initial concentration of bacteria in raw milk and post-processing contamination [2]. When the initial rate of total flora contamination of the milk tank complies with regulatory requirements, all coliforms are eliminated by pasteurization [33].

The non-compliance rate demonstrated by TC in both dairies ranged from $4 \%$ to $6.34 \%$; that of thermotolerant ranged from $3.34 \%$ to $4.34 \%$. A similar result (4.8\%) was reported in Kenya [26] for TC. Relatively high rates were recorded by Aggad et al. [30] (6.52\%) and by Hervert et al. [17] (7.6-26.6\%). Tammam et al. [25] (73.3\%) and Silva et al. [32] registered significantly higher rates (70.8\%). Aggad et al. [30] observed a non-compliance rate similar to TTC $(2.17 \%)$ and Silva et al. [32] observed a higher rate (57.5\%). According to some authors [29,34], the compliance rate could reach $100 \%$, while for another [2], it is the non-compliance rate that can reach $100 \%$. Coliforms do not survive pasteurization but may persist in milk under certain conditions related to pasteurization failures or post-pasteurization recontamination, leading to spoilage or severe foodborne disease $[33,35]$.

The family of EB includes environmental species and other pathogens [36]. The mean levels of EB contamination obtained for the two units (U1 and U2) range from 0.39 to $2.07 \log \mathrm{CFU} / \mathrm{mL}$ and are lower than those reported by Yilma [27] (3.69 $\log$ CFU/mL). The assessment showed that the two hygiene indicator families, EB and TTC, have yielded similar compliance rates. 


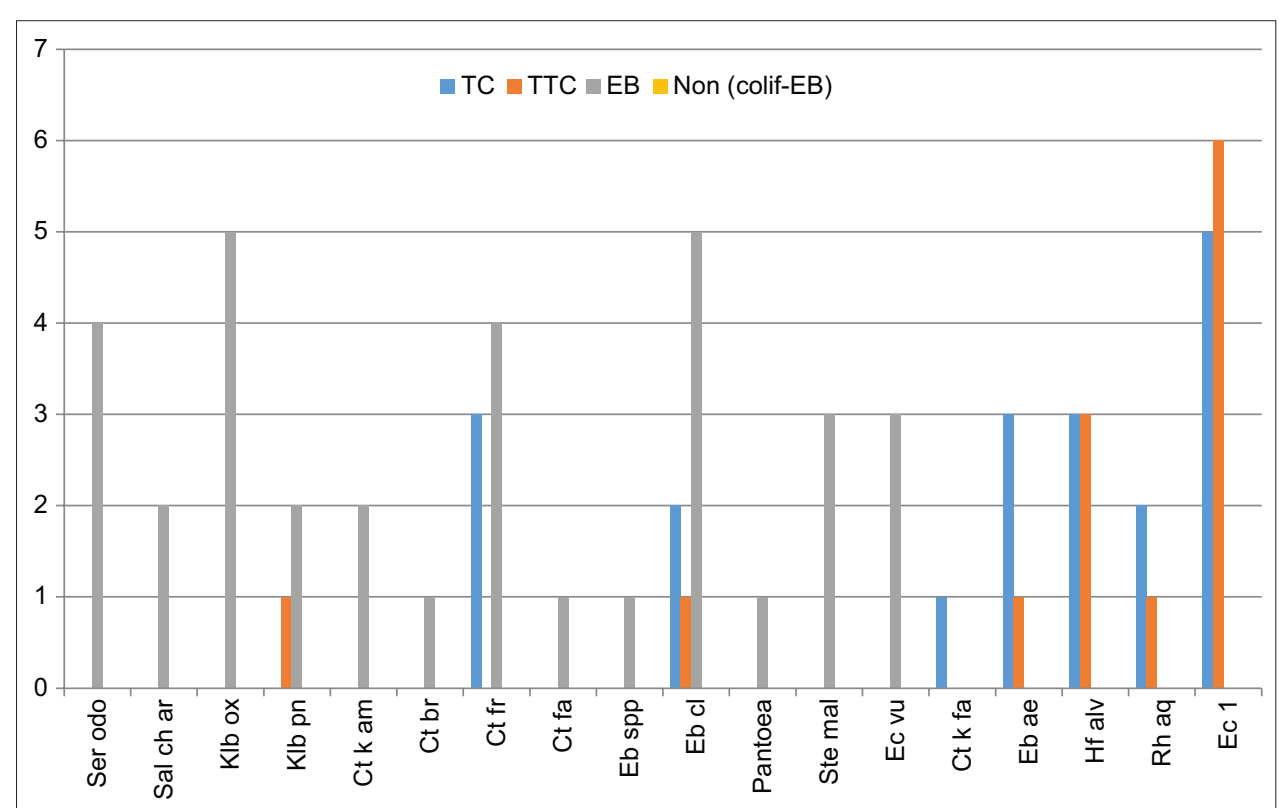

Figure-3: The major bacterial species isolated from the various hygiene indicators in Unit 2. Escherichia coli 1=Ec 1, Enterobacter aerogenes $=\mathrm{Eb}$ ae, Enterobacter cloacae=Eb cl, Enterobacter spp.=Eb spp., Citrobacter freundii=CT fr, Citrobacter braakii $=\mathrm{Ct}$ br, Citrobacter farmeri=Ct fa, Citrobacter koseri/farmeri $=\mathrm{Ct} \mathrm{k} \mathrm{fa}$, Citrobacter koseri/amalonaticus $=\mathrm{Ct}$ $\mathrm{k}$ am, Hafnia alvei=Hf alv, Rahnella aquatilis $=\mathrm{Rh}$ aq, Klebsiella pneumoniae ssp. pneumoniae=KIb pn, Klebsiella oxytoca =KIb ox, Serratia odorifera=Ser odo, Stenotrophomonas maltophilia=Ste mal, Pantoea spp. 1=Pantoea, Salmonella choleraesuis ssp. arizonae $=$ Sal ch ar, Escherichia vulneris $=$ Ec vu.

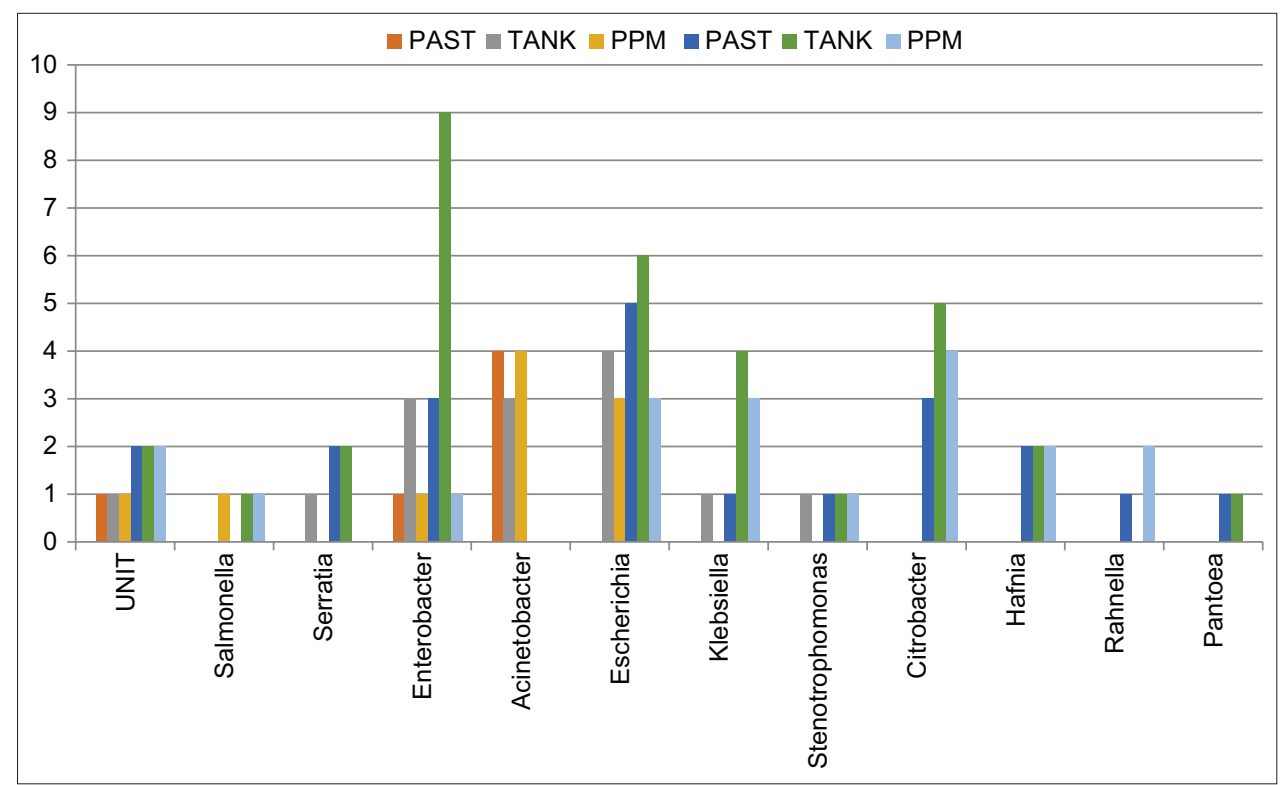

Figure-4: Distribution of Enterobacteriaceae, total coliforms, and thermotolerant coliforms genus during the production process for both units.

\section{Distribution of hygiene indicators in the different stages of production}

The results of the assessment of the evolution of the hygiene indicators, considering the parameters of the indicator/line, showed that there was no variance in the two units along the production line $(p>0.05)$; this suggests that the indicator factor does not reveal a significant difference between the different indicator families used.

Taking into consideration the parameters of the step/indicator, a difference was observed in Unit 1 in all stages showing a significant difference between the different production stages and only in the PAST step in Unit $2(p<0.05)$, suggesting that each step impacts the production line, illustrating the findings of Eneroth et al. [37] who noted that the level of contamination at the PPM packaging stage was higher than at the previous stages and those reported by Aggad et al. [38], where the most contaminated is tanker milk (TANK).

Considering the parameters of the indicator/ indicator, the findings showed that only the combination of TF with other TC, TTC, and EB indicators created a difference $(\mathrm{p}=0.0001)$, confirming the 
previous hypothesis, which showed that there was no difference in their use as hygiene indicators with the same methods. Therefore, the difference between the impact of the TF and the other indicators makes it a reliable indicator [4].

\section{Bacterial diversity of hygiene indicators}

The study of the bacterial profile of the indicator families used reveals that without excluding coliforms, EB contains a wide range of bacterial genera, including the pathogenic genus $C$. freundii; this supports the results of Ranieri and Boor [39] and Eneroth et al. [37]. The genera Escherichia, Klebsiella, Citrobacter, Enterobacter, Serratia, Hafnia, and Rahnella represent the coliform family; these findings are similar to those noted by Hervert et al. [17].

Previous research has shown that Acinetobacter baumannii is a human pathogen that colonizes the skin and upper respiratory tract, suggesting that the contamination found may be of human origin [40]. Using both indicators (coliforms/EB) in both units, the identification of Ec was obtained in the analyzed pasteurized milk, indicating that the contamination is of fecal origin, occurring either during pasteurization failures or during PASTs. Thus, due to fecal contamination during the milking process and poor hygiene practices, E. coli can be found in milk and dairy products [41].

Several Ec strains isolated from raw milk and dairy products cause severe foodborne diseases in humans, including hemolytic uremic syndrome, thrombocytopenic purpura, hemorrhagic colitis, and bloody diarrhea [42]. The genera Klebsiella, Enterobacter, Serratia, and Citrobacter can originate from feces and environmental sources, making them unreliable as indicators of fecal contamination [43]. Because of their low fecal contamination index, many companies have abandoned total coliform detection for food and water analysis [43].

Some countries support the use of EB as an indicator because of the variety of their isolates, including pathogenic species, such as Salmonella spp. and $K$. pneumoniae [17]. Their presence suggests that safety measures are taken during milk processing, and subsequent milk handling has been substandard. Common sources of food contamination by this group of bacteria are feces (animal and human), personal, water, and equipment [44].

The persistence at high levels in the process line of Acinetobacter, Enterobacter, Escherichia, Citrobacter, Klebsiella, and Hafnia indicates that they adhere to milk contact surfaces and is potential persistent or transient colonizers. A. baumannii ability to form biofilms on abiotic surfaces makes it possible to grow sustainably in adverse conditions [40].

Defects in the sanitary design of equipment and facilities can create niches where bacteria are protected from disinfectants and survive without biofilm formation [17]. Over time, the development of Salmonella is not constant, which suggests that its appearance is accidental and have distinct origins. Salmonella can survive for a long period in the environment, more than a year in dust, fuzz, and bovine feces. Salmonella spp. can adhere and form biofilms on different materials during their life cycle, and contaminate the food chain, thus representing a potential danger for consumers. Rodents and insects can also be an important source of Salmonella [45].

\section{Controlling the efficiency of the cleaning and disin- fection protocol}

The control of the cleaning and disinfection process shows a compliance of $99 \%$ in Unit 1 . Unit 2 showed some limitations, especially in the tank. Nevertheless, the results obtained remain acceptable compared with those published in Albania [9] (13.6\% TF and 10.4\% EB) and in Macedonia [12] (13.3\% TF and $16.6 \% \mathrm{~EB})$.

Pasteurized liquid milk contamination is due to several factors, including problems with the design of facilities, cleaning and disinfection practices, personal habits, hygiene, plant air control, and cross-contamination [13]. These results confirm the need for regular monitoring of milk stored in tanks.

\section{Conclusion}

The results of this work indicate that the choice of an indicator depends on the objective. For example, if the aim is to perform routine monitoring of the production process, there is no difference in using either indicator (EB/coliforms). However, the ease of culturing coliforms makes them more practical if the objective is to identify the species involved to determine the pathogenicity of the bacterial species and the potential danger to the consumer; the use of EBs remains the most appropriate. Depending on the performance of the heat treatment applied, the multiplication of pathogens is either prevented or stimulated.

As the quality of the products promised to the consumer is often dependent on the control of the finished products, there are many disadvantages to this approach, such as the appearance of food poisoning cases and the increase in the cost of production concerning the recalled non-compliant products. Therefore, it is recommended that the competent authorities generalize the use of process hygiene indicators that allow the efficiency or non-efficiency of manufacturing processes to be verified to avoid multiplying conformity controls of finished products.

\section{Authors' Contributions}

RS: Performed the study and drafted and revised the manuscript under the supervision of HTM and BL. RS and BL: Interpreted the results. All authors read and approved the final manuscript.

\section{Acknowledgments}

This study was financially supported by Laboratory of Food Hygiene and Quality Insurance 
System (HASAQ), Algeria. The authors are thankful to Aek Eddoud for help in the statistical analysis. In addition, the authors would like to express sincere thanks to the milk industries, especially Mme Linda Gounane, for their help in collecting data for this study.

\section{Competing Interests}

The authors declare that they have no competing interests.

\section{Publisher's Note}

Veterinary World remains neutral with regard to jurisdictional claims in published and institutional affiliation.

\section{References}

1. Lemma, D.H., Mengistu, A., Kuma, T. and Kuma, B. (2018) Improving milk safety at farm-level in an intensive dairy production system: Relevance to smallholder dairy producers. Food Qual. Saf., 2(3): 135-143.

2. Ahmed, S., Zim, A.F.M., Rahman, S., Ghosh, S., Chhetri, A. and Ali, M.S. (2019) Quality and safety assessment of Bangladeshi pasteurized milk. J. Food Qual. Hazards Control., 6(1): 25-29.

3. Merwan, A., Nezif, A. and Metekia, T. (2018) Review on milk and milk product safety, quality assurance and control. Int. J. Livest. Prod., 9(4): 67-78.

4. Sarkar, S. (2015) Microbiological considerations: Pasteurized milk. Int. J. Dairy Sci., 10(5): 206-218.

5. Fox, E.M., Fanning, S., Corsetti, A. and Jordan, K. (2017) Editorial: Microbial food safety along the dairy chain. Front. Microbiol., 8: 1612.

6. Jiao, X., Zhu, J., Huang, J. and Dong, Q. (2017) In: Jen, J.J., Chen, J., editors. Microbiological Risk Assessment in Food Food Safety in China. John Wiley and Sons, Ltd., Chichester, UK. p287-305.

7. Golić, B., Golić, M. and Ilić, T. (2019) Microbiological criteria in the manufacture of pasteurized milk. Vet. J. Republik Srpske, 19(1): 90-97.

8. Sandrou, D.K. and Arvanitoyannis, I.S. (2000) Implementation of hazard analysis critical control point (HACCP) to the dairy industry: Current status and perspectives. Food Rev. Int., 16(1): 77-111.

9. Anon. (2018) Evaluation of the microbial parameters and hygiene status of dairy establishments in Tirana region. Eur. Acad. Res., 6(4): 1629-1643.

10. Malek, F., Moussa-Boudjemâa, B., Khaouani-Yousfi, F., Kalai, A. and Kihel, M. (2012) Microflora of biofilm on Algerian dairy processing lines: An approach to improve microbial quality of pasteurized milk. Afr. J. Microbiol. Res., 6(17): 3836-3844.

11. Nada, S., Ilija, D., Igor, T., Jelena, M. and Ruzica, G. (2012) Implication of food safety measures on microbiological quality of raw and pasteurized milk. Food Control, 25(2): 728-731.

12. Ljupco, A., Dean, J., Marija, R., Mirko, P., Sandra, M. and Pavle, S. (2012) Assessment of the microbial parameters along the production phases at a dairy plant. Maced. Vet. Rev., 35(1): 23-28.

13. Martin, N.H., Boor, K.J. and Wiedmann, M. (2018) Symposium review: Effect of post-pasteurization contamination on fluid milk quality. J. Dairy Sci., 101(1): 861-870.

14. Martin, N.H., Trmčić, A., Hsieh, T.H., Boor, K.J. and Wiedmann, M. (2016) The evolving role of coliforms as indicators of unhygienic processing conditions in dairy foods. Front. Microbiol., 7: 1549.

15. AFSSA. (2008) Recommendations for the Development of
Criteria Microbiological Process Hygiene. 2008-SA-0083. AFSSA. p5.

16. Hervert, C.J., Alles, A.S., Martin, N.H., Boor, K.J. and Wiedmann, M. (2016) Evaluation of different methods to detect microbial hygiene indicators relevant in the dairy industry. J. Dairy Sci., 99(9): 7033-7042.

17. Hervert, C.J., Martin, N.H., Boor, K.J. and Wiedmann, M. (2017) Survival and detection of coliforms, Enterobacteriaceae, and gram-negative bacteria in Greek yogurt. J. Dairy Sci., 100(2): 950-960.

18. International Organization for Standardization. (2004) 18593:2004. Microbiology of Food and Animal Feeding Stuffs-Horizontal Methods for Sampling Techniques from Surfaces Using Plates and Swabs. International Organization for Standardization, Geneva, Switzerland.

19. International Organization for Standardization. (2006) 4833:2006. Microbiology of Food and Animal Feeding Stuffs-Horizontal Methods for the Enumeration of Microorganisms Colony Count Technique at $30^{\circ} \mathrm{C}$. International Organization for Standardization, Geneva, Switzerland.

20. International Organization for Standardization. (2006) 4832:2006. Microbiology of food and animal Feeding Stuffs-Horizontal Methods for the Enumeration of Coliform Colony Count Technique. International Organization for Standardization, Geneva, Switzerland.

21. International Organization for Standardization. (2017) 21528-2:2017 Microbiology of the Food Chain Horizontal Methods for the Detection and Enumeration of Enterobacteriaceae-Part 2:Colony-count Technique. International Organization for Standardization, Geneva, Switzerland.

22. Official Journal of the Algerian Republic. (1998) Interministerial Decree: The Microbiological Criteria Regarding Foodstuffs of 24 January 1998. No.35. Official Journal of the Algerian Republic, Algeria.

23. Official Journal of the Algerian Republic. (2017) Interministerial Decree: The Microbiological Criteria Regarding Foodstuffs of 04 October 2016. No.39. Official Journal of the Algerian Republic, Algeria.

24. Belli, P., Cantafora, A.F.A., Stella, S., Barbieri, S. and Crimella, C. (2013) Microbiological survey of milk and dairy products from a small scale dairy processing unit in Maroua (Cameroon). Food Control, 32: 366-370.

25. Tammam, A.A., Taha, N.M., Wahba, N.M. and Moustafa, M.K. (2015) Microbiological characterization of raw and pasteurized milk. Egypt. J. Dairy Sci., 43(1): 9-15.

26. Wanjala, G. (2017) Microbiological quality and safety of raw and pasteurized milk marketed in and around Nairobi Region. Afr. J. Food Agric. Nutr. Dev., 17(1): 11518-11532.

27. Yilma, Z. (2012) In: De Souza Da Cunha LR, editor. Microbial Properties of Ethiopian Marketed Milk and Milk Products and Associated Critical Points of Contamination: An Epidemiological Perspective Epidemiology Insights. InTech, London.

28. Berhe, G., Wasihun, A.G., Kassaye, E. and Gebreselasie, K. (2020) Milk-borne bacterial health hazards in milk produced for commercial purpose in Tigray, Northern Ethiopia. BMC Public Health, 20: 894.

29. Ahmed, K. and Abdellatif, N. (2013) Quality control of milk in the dairy industry. World J. Dairy Food Sci., 8(1): 18-26.

30. Aggad, H., Bridja, M., Aek, B., Benaouali, M. and Djebli, A. (2010) Some quality aspects of pasteurized milk in Algeria. World J. Dairy Food Sci., 5(1): 21-24.

31. Cissé, H., Muandze-Nzambe, J.U., Somda, N.S., Sawadogo, A., Drabo, S.M., Tapsoba, F., Zongo, C., Traore, Y. and Savadogo, A. (2019) Assessment of safety and quality of fermented milk of camels, cows, and goats sold and consumed in five localities of Burkina Faso. Vet. World, 12(2): 295-304.

32. Silva, R., Cruz, A.G., Faria, J.A.F., Moura, M.M.L., 
Carvalho, L.M.J., Water, E.H.M. and Sant'Ana, A.S. (2010) Pasteurized milk: Efficiency of pasteurization and its microbiological conditions in Brazil. Foodborne Pathog. Dis., 7(2): 217-219.

33. Pantoja, J.C.F., Reinemann, D.J. and Ruegg, P.L. (2011) Factors associated with coliform count in unpasteurized bulk milk. J. Dairy Sci.,94(6): 2680-2691.

34. Ak, B. and Tg, R. (2011) Isolation of psychrotrophic multiple drug-resistant Pseudomonas from pasteurized milk. Vet. World, 4(8): 349-352.

35. Hw, W. and Am, A. (2017) Microbial and physicochemical qualities of pasteurized milk. J. Food Process. Technol., 8(1): 18-26.

36. Westling, M., Danielsson-Tham, M.L., Jass, J., Nilsen, A., Öström, ̊. and Tham, W. (2016) Contribution of Enterobacteriaceae to sensory characteristics in soft cheeses made from raw milk. Proc. Food Sci., 7: 17-20.

37. Eneroth, Å., Christiansson, A., Brendehaug, J. and Molin, G. (1998) Critical contamination sites in the production line of pasteurised milk, with reference to the psychrotrophic spoilage flora. Int. Dairy J., 8: 829-834.

38. Aggad, H., Mahouz, F., Ammar, Y.A. and Kihal, M. (2009) Evaluation de la qualité hygiénique du lait dans l'ouest algérien. Rev. Méd. Vét., 160 (12): 590-595.

39. Ranieri, M.L. and Boor, K.J. (2009) Short communication:
Bacterial ecology of high-temperature, short-time pasteurized milk processed in the United States. J. Dairy Sci., 92(10): 4833-4840.

40. Howard, A., O'Donoghue, M., Feeney, A. and Sleator, R.D. (2012) Acinetobacter baumannii: An emerging opportunistic pathogen. Virulence, 3(3): 243-250.

41. Chaleshtori, F.S., Arani, N.M., Aghadavod, E., Naseri, A. and Chaleshtori, R.S. (2017) Molecular characterization of Escherichia coli recovered from traditional milk products in Kashan, Iran. Vet. World, 10(10): 1264-1268.

42. Ismail, Z.B. and Abutarbush, S.M. (2020) Molecular characterization of antimicrobial resistance and virulence genes of Escherichia coli isolates from bovine mastitis. Vet. World, 13(8): 1588-1593.

43. Masiello, S.N., Martin, N.H., Trmčić, A., Wiedmann, M. and Boor, K.J. (2016) Identification and characterization of psychrotolerant coliform bacteria isolated from pasteurized fluid milk. J. Dairy Sci., 99(1): 130-140.

44. Yilma, Z. and Faye, B. (2006) Handling and microbial load of cow's milk and Irgo fermented milk collected from different shops and producers in central highlands of Ethiopia. Ethiopian J. Anim. Prod., 6(2): 7-82.

45. Ćwiek, K., Bugla-Płoskońska, G. and Wieliczko, (2019) A Salmonella biofilm development: Structure and significance. Postepy Hig. Med. Dosw., 73: 937-943. 